\title{
Trends in isolated lumbar spinal stenosis surgery among working US adults aged 40-64 years, 2010-2014
}

\author{
Micheal Raad, MD, ${ }^{1}$ Callum J. Donaldson, BSc, ${ }^{2}$ Mostafa H. El Dafrawy, MD, ${ }^{1}$ \\ Daniel M. Sciubba, MD, ${ }^{1}$ Lee H. Riley III, MD, ${ }^{1}$ Brian J. Neuman, MD, ${ }^{1}$ Khaled M. Kebaish, MD, ${ }^{1}$ and \\ Richard L. Skolasky, ScD ${ }^{1}$
}

1'Department of Orthopaedic Surgery, The Johns Hopkins University, Baltimore, Maryland; and 2King's College London, London, United Kingdom

\begin{abstract}
OBJECTIVE Recommendations for the surgical treatment of isolated lumbar spinal stenosis (LSS) (i.e., in the absence of concomitant scoliosis or spondylolisthesis) are unclear. The aims of this study were to investigate trends in the surgical treatment of isolated LSS in US adults and determine implications for outcomes.
\end{abstract}

METHODS The authors analyzed inpatient and outpatient claims from the Truven Health Analytics MarketScan Commercial Claims and Encounters Database for 20,279 patients aged 40-64 years who underwent surgery for LSS between 2010 and 2014. Only patients with continuous 12-month insurance coverage after surgery were included. The rates of decompression with arthrodesis versus decompression only and of simple (1- or 2-level, single-approach) versus complex (> 2-level or combined-approach) arthrodesis were analyzed by year and geographic region. These trends were further analyzed with respect to complications, length of hospital stay, payments made to the hospital, and patient discharge status. Statistical significance was set at $p<0.05$.

RESULTS The proportion of patients who underwent decompression with arthrodesis compared with decompression only increased significantly and linearly from 2010 to 2014 (OR 1.08; 95\% Cl 1.06-1.10). Arthrodesis was more likely to be complex rather than simple with each subsequent year (OR 1.4; 95\% $\mathrm{Cl} 1.33-1.49)$. This trend was accompanied by an increased likelihood of postoperative complications (OR 1.11; 95\% Cl 1.02-1.21), higher costs (payments increased by a mean of US $\$ 1633$ per year; $95 \% \mathrm{CI} 1327-1939$ ), and greater likelihood of being discharged to a skilled nursing facility as opposed to home (OR 1.11; 95\% Cl 1.03-1.20). The South and Midwest regions of the US had the highest proportions of patients undergoing arthrodesis (48\% and $42 \%$, respectively). The mean length of hospital stay did not change significantly $(p=0.324)$.

CONCLUSIONS From 2010 to 2014, the proportion of adults undergoing decompression with arthrodesis versus decompression only for the treatment of LSS increased, especially in the South and Midwest regions of the US. A greater proportion of these fusions were complex and were associated with more complications, higher costs, and a greater likelihood of being discharged to a skilled nursing facility.

https://thejns.org/doi/abs/10.3171/2018.1.SPINE17964

KEYWORDS complex fusion; hospital payments; lumbar spinal stenosis; outcomes; trends

A FTER the introduction of pedicle screw fixation in the early 1990s, surgery for lumbar spinal stenosis (LSS) became the fastest-growing surgery. ${ }^{5,22}$ Spinal stenosis subsequently became the most common indication for spinal surgery in elderly patients. ${ }^{1}$ From 2000 to 2014, the estimated national cost of LSS surgery increased from $\$ 1.8$ to $\$ 8.2$ billion as surgery for LSS rose from $0.2 \%$ to $0.3 \%$ of all inpatient procedures performed in the US (https://hcupnet-archive.ahrq.gov).
Patients with isolated LSS (i.e., in the absence of concomitant scoliosis or spondylolisthesis) can be treated nonoperatively using various modalities, including pain medication, physical therapy, and epidural steroid injections. Patients can also undergo decompressive spinal surgery with or without arthrodesis. ${ }^{4}$ It is well established that at mid- to long-term follow-up, surgical decompression is associated with clinical outcomes superior to those achieved with nonoperative therapy., ${ }^{1,14,18,24}$ However, the choice of

ABBREVIATIONS CCI = Charlson Comorbidity Index; ICD-9 = International Classification of Diseases, Ninth Revision; LSS = lumbar spinal stenosis; SNF = skilled nursing facility; USD = US dollar

SUBMITTED August 31, 2017. ACCEPTED January 3, 2018.

INCLUDE WHEN CITING Published online May 25, 2018; DOI: 10.3171/2018.1.SPINE17964. 
surgical procedure is a matter of debate. Although decompression with arthrodesis reduces the motion of spinal segments that may cause pain, its use in isolated LSS has not been shown to produce superior outcomes to decompression alone and is generally not recommended in that particular setting. ${ }^{27,15,16,20}$ Furthermore, arthrodesis has been associated with a higher rate of major postoperative complications, longer hospital stay, and greater use of health care resources compared with decompression alone. ${ }^{2,6,17}$ Previous studies have shown that the decision to perform arthrodesis is determined largely by surgeon preference ${ }^{10}$ and that it varies by geographic region. ${ }^{13}$

Despite a lack of evidence to support its use and the undesirable effects it may cause, the use of arthrodesis for LSS treatment in the US for patients aged $\geq 65$ years has risen substantially in recent years. ${ }^{6}$ A similar trend has been observed in patients aged $>18$ years in Australia. ${ }^{17}$ However, it is unclear whether the trend toward an increased rate of arthrodesis for LSS is happening in working-age patients in the US and whether this potential increase in the number of complex procedures has similar adverse associations. Patients aged 40-64 years constitute a large proportion of the US workforce. Their share of the gross domestic product was estimated to be $30 \%$ in $2010 .{ }^{12}$ Hence, more accurate assessment of the risks and benefits of arthrodesis for isolated LSS in this population may have far-reaching economic consequences.

Our goals were to identify temporal trends in the following: 1) the incidence of surgery for isolated LSS; 2) the type of surgery performed; 3 ) the complexity of LSS procedures; 4) the length of hospital stay, postoperative complication rates, and discharge status after surgical treatment of LSS, as well as the costs of surgical treatment of LSS; and 5) geographic variations in the type of surgery performed for LSS.

\section{Methods}

This research does not qualify as human subjects research and is subsequently exempt from institutional review board approval.

\section{Patient Sample}

Our patient sample was derived from inpatient and outpatient claims between 2010 and 2014 from the Truven Health Analytics MarketScan Commercial Claims and Encounters Database, which includes data on commercially insured members $<65$ years of age. We included patients $>40$ years of age with continuous 12-month insurance coverage after surgery. The International Classification of Diseases, Ninth Revision (ICD-9) code 724.02 was used to identify patients who underwent surgery for "spinal stenosis of the lumbar region" as the only principal diagnosis. We excluded patients with concomitant diagnoses such as scoliosis or spondylolisthesis.

\section{Surgery Incidence and Type}

The incidence of surgery was calculated as the proportion of patients who underwent LSS surgery to the total number of eligible enrollees during each 1-year period. Surgery was categorized as decompression only (ICD-9 code 03.09 or 80.51 ) or decompression with fusion (code $81.06,81.07,81.08,81.63$, or 81.64).

\section{Complications and Discharge Status}

Inpatient medical complications were the following: cardiopulmonary resuscitation (ICD-9 code 9393 or 9960), endotracheal intubation (code 9604), cardiopulmonary arrest (code 4275 or 9971), acute myocardial infarction (code 410), respiratory failure (code 51881), pulmonary embolism (code 41511), pneumonia (code 482), stroke (code 99702), and wound infection or dehiscence (code 9981, 9983, 9985, or 8622). Patients were categorized as being discharged to home or to a skilled nursing facility (SNF).

\section{Regional Analysis}

Geographical regions were assigned according to the location of patient residence. They were divided into the 4 geographic regions used by the US Census Bureau: Northeast (Connecticut, Maine, Massachusetts, New Hampshire, Rhode Island, Vermont, New Jersey, New York, and Pennsylvania); Midwest (Illinois, Indiana, Iowa, Kansas, Michigan, Minnesota, Missouri, Nebraska, North Dakota, Ohio, South Dakota, and Wisconsin); South (Alabama, Arkansas, Delaware, District of Columbia, Florida, Georgia, Kentucky, Louisiana, Maryland, Mississippi, North Carolina, Oklahoma, South Carolina, Tennessee, Texas, Virginia, and West Virginia); and West (Alaska, Arizona, California, Colorado, Hawaii, Idaho, Montana, Nevada, New Mexico, Oregon, Utah, Washington, and Wyoming).

\section{Payments and Length of Hospital Stay}

To estimate the use of health care resources, we analyzed payments made to the hospitals (as opposed to charges) in US dollars (USD) and the length of postoperative hospital stay in days. Inflation rates were adjusted according to the consumer price index, and all dollars were subsequently expressed in 2014 USD equivalents.

\section{Statistical Analysis}

Changes during the 5-year period in the characteristics and outcomes of patients who underwent surgery for LSS were assessed using multivariate regression models controlling for patient age and sex. Student t-tests were used to compare group means, and chi-square tests were used to compare proportions. Given the large sample size, care must be taken when interpreting statistically significant but not clinically important results. Statistical significance was set at $p<0.05$. Statistical analyses were performed using Stata software, version 15 (StataCorp LP).

\section{Results}

\section{Patient Sample}

The annual incidence of LSS surgery (per 1000 people) ranged from a low of 1.2 in 2014 to a high of 1.8 in 2011 and 2012 (Table 1). In total, 20,279 patients underwent surgery for LSS and were included in the study. The mean $( \pm$ SD) patient age was $56 \pm 6$ years, and 9001 patients (44\%) were women. The proportion of women versus men undergoing LSS surgery did not change significantly over 
TABLE 1. Surgery type and incidence data by year for 20,279 patients who underwent surgery for LSS

\begin{tabular}{lll}
\hline \multicolumn{1}{c}{ Parameter } & No. $(\%)^{*}$ & Incidence $\dagger$ \\
\hline Decompression only & & \\
\hline 2010 & $2897(61)$ & \\
\hline 2011 & $3003(61)$ & \\
\hline 2012 & $2841(61)$ & \\
\hline 2013 & $1885(58)$ & \\
\hline 2014 & $1357(51)$ & \\
\hline Overall & $11,983(59)$ & \\
\hline Decompression w/ arthrodesis & & \\
\hline 2010 & $1887(40)$ & \\
\hline 2011 & $1919(39)$ & \\
\hline 2012 & $1830(39)$ & \\
\hline 2013 & $1368(42)$ & \\
\hline 2014 & $1292(49)$ & 1.7 \\
\hline Overall & $8296(41)$ & 1.8 \\
\hline Overall surgery incidence & & 1.8 \\
\hline 2010 & & 1.5 \\
\hline 2011 & & \\
\hline 2012 & & \\
\hline 2013 & & \\
\hline 2014 & & \\
\hline Overall & & \\
\hline
\end{tabular}

Data from the Truven Health Analytics MarketScan Commercial Claims and Encounters Database, 2010-2014.

* Complex fusions were those involving a combined anteroposterior approach and/or $>2$ spinal levels. Percentages represent the proportion of complex fusions out of the total number of fusions performed

† Per 1000 eligible enrollees during each 1-year period. Annual enrollment was 2.75 million in 2010, 2.76 million in 2011, 2.67 million in 2012, 2.12 million in 2013, and 2.20 million in 2014.

time ( $p=0.082)$. Similarly, the mean Charlson Comorbidity Index (CCI) values were similar throughout the study period $(p=0.319)$. Although there was a statistically significant decrease in age over time, this difference was not clinically important (differences were $-0.12,-0.19$, and $-0.06, \mathrm{p}<0.001)$

\section{Surgery Incidence and Type}

Of the 20,279 patients, 8296 (41\%) underwent decompression with arthrodesis (Table 1). Compared with patients who underwent decompression only, patients who underwent decompression with arthrodesis were more likely to be women $(51 \%$ vs $40 \%, \mathrm{p}<0.001)$ (Table 2$)$. The proportion of patients who underwent decompression with arthrodesis as opposed to decompression only increased significantly over time (OR 1.08, p < 0.001) (Fig. 1). Similarly, arthrodesis was more likely to be complex rather than simple with each subsequent year (OR 1.4; 95\% CI $1.33-1.49)$.

\section{Complications and Discharge Status}

During the study period, there was a significant increase in the likelihood of having a postoperative medical
TABLE 2. Characteristics and outcomes of patients who underwent decompression only $(n=11,983)$ or decompression with arthrodesis $(n=8296)$ for LSS

\begin{tabular}{|c|c|c|c|}
\hline Parameter & Mean \pm SD & $\begin{array}{c}\text { No. of } \\
\text { Patients } \\
(\%)\end{array}$ & $\begin{array}{c}p \\
\text { Value }\end{array}$ \\
\hline \multicolumn{4}{|l|}{ Patient characteristics } \\
\hline \multicolumn{4}{|l|}{ Age, yrs } \\
\hline Decompression only & $57 \pm 6$ & & \multirow[b]{2}{*}{$<0.001$} \\
\hline $\begin{array}{l}\text { Decompression w/ } \\
\text { arthrodesis }\end{array}$ & $56 \pm 6$ & & \\
\hline \multicolumn{4}{|l|}{ Female sex } \\
\hline Decompression only & & $4743(40)$ & \multirow[b]{2}{*}{$<0.001$} \\
\hline $\begin{array}{l}\text { Decompression w/ } \\
\text { arthrodesis }\end{array}$ & & $4258(51)$ & \\
\hline \multicolumn{4}{|l|}{$\mathrm{CCl}$ score } \\
\hline Decompression only & $0.46 \pm 0.82$ & & \multirow[b]{2}{*}{0.074} \\
\hline $\begin{array}{l}\text { Decompression w/ } \\
\text { arthrodesis }\end{array}$ & $0.43 \pm 0.80$ & & \\
\hline \multicolumn{4}{|l|}{ Outcomes } \\
\hline \multicolumn{4}{|l|}{ Complication } \\
\hline Decompression only & & $145(1.2)$ & \multirow[b]{2}{*}{$<0.001$} \\
\hline $\begin{array}{l}\text { Decompression w/ } \\
\text { arthrodesis }\end{array}$ & & $156(1.9)$ & \\
\hline \multicolumn{4}{|c|}{ Length of hospital stay, days } \\
\hline Decompression only & $2.3 \pm 2.6$ & & \multirow[b]{2}{*}{$<0.001$} \\
\hline $\begin{array}{l}\text { Decompression w/ } \\
\text { arthrodesis }\end{array}$ & $3.5 \pm 3.5$ & & \\
\hline \multicolumn{4}{|l|}{ Discharge to SNF } \\
\hline Decompression only & & $171(1.4)$ & \multirow[b]{2}{*}{$<0.001$} \\
\hline $\begin{array}{l}\text { Decompression w/ } \\
\text { arthrodesis }\end{array}$ & & $211(2.5)$ & \\
\hline \multicolumn{4}{|l|}{ Payment, USD } \\
\hline Decompression only & $14,000 \pm 13,000$ & & \multirow[b]{2}{*}{$<0.001$} \\
\hline $\begin{array}{l}\text { Decompression w/ } \\
\text { arthrodesis }\end{array}$ & $48,000 \pm 35,000$ & & \\
\hline
\end{tabular}

Data from the Truven Health Analytics MarketScan Commercial Claims and Encounters Database, 2010-2014.

complication (OR 1.11, $\mathrm{p}=0.013$ ) (Table 3). Similarly, the likelihood of being discharged to an SNF as opposed to home also increased significantly over time (OR 1.11, $\mathrm{p}=$ 0.005). Compared with decompression only, decompression with arthrodesis was associated with significantly higher rates of inpatient complications $(1.9 \%$ vs $1.2 \%$, p < $0.001)$ and discharge to an SNF $(2.5 \%$ vs $1.4 \%, \mathrm{p}<0.001)$ (Table 2).

\section{Geographic Variation}

The proportion of patients who underwent decompression with arthrodesis versus decompression only for isolated LSS differed significantly by US geographic region $(\mathrm{p}<0.001)$. The regions with the highest proportion of patients undergoing decompression with arthrodesis were the Midwest (42\%) and South (48\%), whereas the regions 


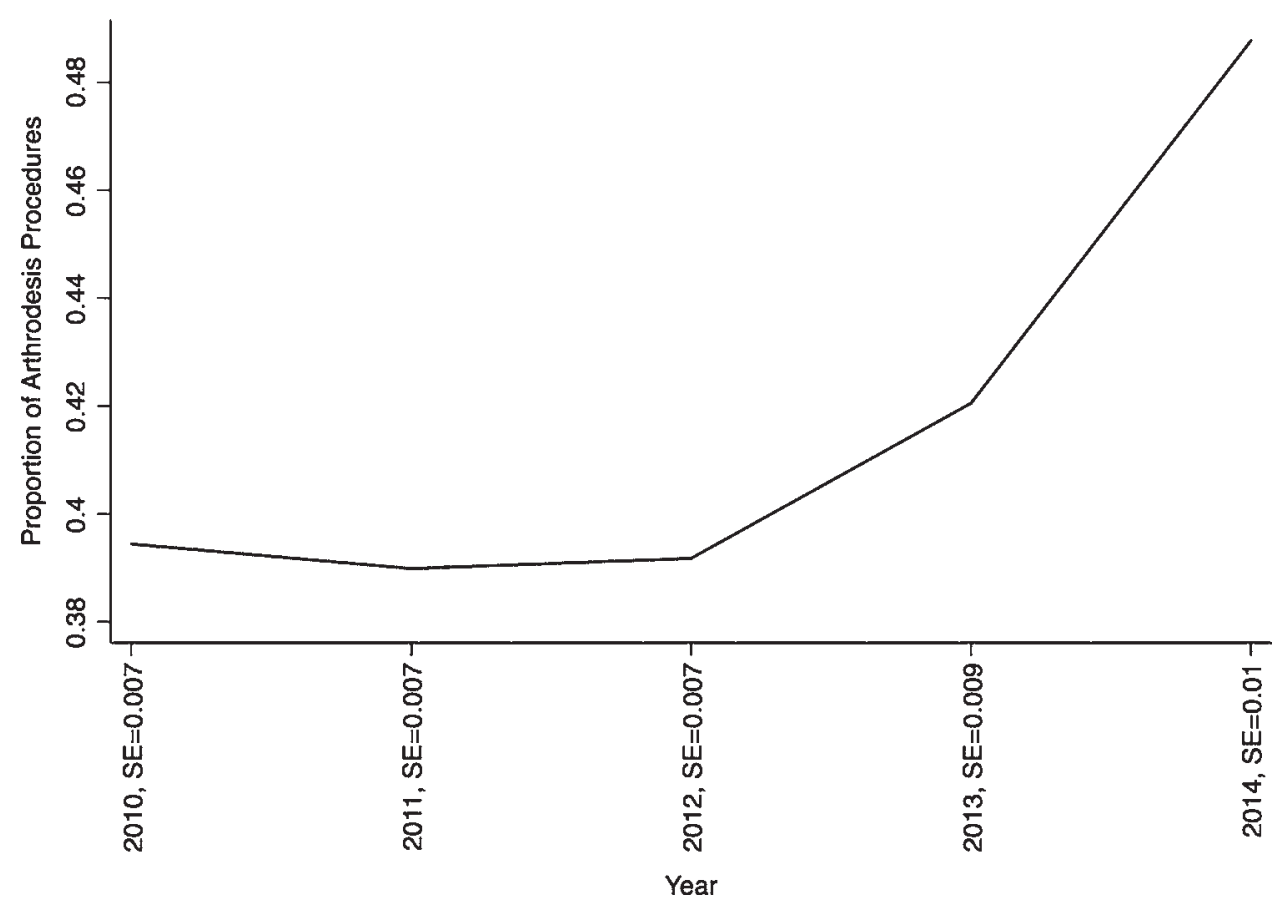

FIG. 1. Proportion of 20,279 patients aged $40-64$ years who underwent surgical decompression for LSS whose treatment also included arthrodesis. This proportion increased significantly and linearly during the 5-year study period.

with the lowest rates of arthrodesis were the Northeast (36\%) and West (31\%). After controlling for age, sex, and $\mathrm{CCI}$, patients were significantly more likely to undergo arthrodesis if they resided in the Midwest (OR 1.3, p < $0.001)$ or the South (OR 1.6, $\mathrm{p}<0.001)$ compared with the Northeast (Fig. 2).

\section{Payments and Length of Hospital Stay}

Mean hospital payments for LSS surgery increased significantly by a mean of US $\$ 1633$ per year $(95 \%$ CI 1327-1939, p < 0.001) (Table 3) and were higher by almost fourfold for patients who underwent decompression with arthrodesis versus decompression only $(\$ 48,000 \pm$ $\$ 35,000$ vs $\$ 14,000 \pm \$ 13,000, \mathrm{p}<0.001$ ) (Table 2).

Mean length of hospital stay did not change significantly during the study period $(\mathrm{p}=0.187)$ (Table 3); however, it was significantly longer for patients who underwent decompression with arthrodesis versus those who underwent decompression alone $(3.5 \pm 3.5$ vs $2.3 \pm 2.6$ days, $\mathrm{p}$ $<0.001)$ (Table 2).

\section{Discussion}

In our sample of US adults aged 40-64 years, the likelihood of undergoing arthrodesis for isolated LSS increased significantly from 2010 to 2014. These changes were accompanied by rising medical costs, higher complication rates, and increased rates of discharge to an SNF.

In 2010, Deyo et al. ${ }^{6}$ reported an increase in the proportion of complex fusions among the US elderly population from 2002 to 2007 . Our results similarly reflect a rise in the proportion of complex procedures for LSS in patients aged 40-64 years. A similar trend in the adult Australian population between 2003 and 2013 has been reported. ${ }^{17}$
It is unclear what is causing the increase in the proportion of complex surgeries. We hypothesize that contributing factors may be financial incentives that are part of a changing physician reimbursement system, the influence of key opinion leaders, and the marketing of new surgical devices. ${ }^{5}$ A worsening of patients' disease state over time or a change in disease severity seems implausible because the same ICD-9 diagnosis code for isolated LSS was used throughout the study.

The treatment approach for degenerative disease of the lumbar spine varies substantially by surgeon and specialty. ${ }^{9,10}$ However, complex procedures in the elderly are associated with high costs, complication rates, and readmission rates. ${ }^{6}$ Although it might be plausible that younger patients better tolerate complex procedures, our results show that patients aged 40-64 years who underwent arthrodesis had significantly longer hospital stays, higher rates of inpatient complications, and higher payments by the insurance provider.

During the 5-year study period, the age, sex, and CCI of patients who underwent surgery for LSS did not change in a clinically important manner. However, patients who underwent decompression with arthrodesis were more likely to be women. The influences of patient sex on procedure choice remain unclear. The higher likelihood of undergoing arthrodesis for female patients may be supported by the notion that these decisions are based on surgeon preference, patient expectations, and cultural factors, as well as a possibly higher association of instability with LSS that might have been underestimated by ICD-9 coding. ${ }^{19}$

The type of procedure performed for LSS in the US elderly population has been shown to differ by geographic location., ${ }^{3,23}$ Weinstein et al. ${ }^{23}$ reported that arthrodesis rates among elderly patients were highest in many Mid- 
TABLE 3. Outcomes by year for 20,279 patients who underwent surgery for LSS

\begin{tabular}{|c|c|c|c|c|c|}
\hline \multirow[b]{2}{*}{ Outcome by Year } & \multirow[b]{2}{*}{ No. (\%) } & \multirow[b]{2}{*}{ Mean \pm SD } & \multicolumn{3}{|c|}{ Change From 2010 to 2014} \\
\hline & & & OR $(95 \% \mathrm{Cl})^{*}$ & $\beta(95 \% \mathrm{Cl})^{*}$ & $\mathrm{p}$ Value \\
\hline \multicolumn{6}{|l|}{ Complication } \\
\hline 2010 & $59(1.2)$ & & \multirow{5}{*}{$1.11(1.02$ to 1.21$)$} & & \multirow{5}{*}{0.013} \\
\hline 2011 & $74(1.5)$ & & & & \\
\hline 2012 & $56(1.2)$ & & & & \\
\hline 2013 & $65(2.0)$ & & & & \\
\hline 2014 & $47(1.8)$ & & & & \\
\hline Overall & $301(1.5)$ & & & & \\
\hline \multicolumn{6}{|c|}{ Length of hospital stay, days } \\
\hline 2010 & & $2.8 \pm 3.4$ & & \multirow{5}{*}{$0.02(-0.01$ to 0.05$)$} & \multirow{5}{*}{0.187} \\
\hline 2011 & & $2.7 \pm 2.8$ & & & \\
\hline 2012 & & $2.7 \pm 3.2$ & & & \\
\hline 2013 & & $2.9 \pm 3.0$ & & & \\
\hline 2014 & & $2.9 \pm 3.0$ & & & \\
\hline Overall & & $2.3 \pm 2.6$ & & & \\
\hline \multicolumn{6}{|l|}{ Discharge to SNF } \\
\hline 2010 & $84(1.8)$ & & \multirow{5}{*}{1.11 (1.03 to 1.20$)$} & & \multirow{5}{*}{0.005} \\
\hline 2011 & $81(1.6)$ & & & & \\
\hline 2012 & $83(1.8)$ & & & & \\
\hline 2013 & $67(2.1)$ & & & & \\
\hline 2014 & $67(2.5)$ & & & & \\
\hline Overall & $382(1.9)$ & & & & \\
\hline \multicolumn{6}{|l|}{ Payment, USD } \\
\hline 2010 & & $26,000 \pm 28,000$ & & \multirow{6}{*}{1633 (1327 to 1939) } & \multirow{6}{*}{$<0.001$} \\
\hline 2011 & & $27,000 \pm 30,000$ & & & \\
\hline 2012 & & $27,000 \pm 28,000$ & & & \\
\hline 2013 & & $31,000 \pm 30,000$ & & & \\
\hline 2014 & & $32,000 \pm 35,000$ & & & \\
\hline Overall & & $28,000 \pm 30,000$ & & & \\
\hline
\end{tabular}

Data from the Truven Health Analytics MarketScan Commercial Claims and Encounters Database, 2010-2014.

* Adjusted for patient age and sex.

west and Southern states compared with the Northeast and the West. Our results support that finding in a younger population. Interestingly, the higher rates of arthrodesis in the South and Midwest compared with the West and Northeast were reported in $1994,{ }^{22}$ and this trend seems to persist. There is no evidence that the indication for surgery and subsequently the type of procedure performed varied by geographic location.

Given that patient and surgeon preferences have been shown to vary by geographic location, ${ }^{8,21}$ we believe that local training and variations in physician-patient interactions may have contributed to this variability.

This study has potential limitations, including those inherent in a retrospective design. We analyzed administrative claims data in which ICD-9 diagnostic and procedure codes were used, and such codes may lack the clinical specificity to represent disease states accurately. However, we believe that using the same ICD-9 codes consistently throughout the study addresses this limitation because it is unlikely that the same code would reflect more com- plex indications for surgery over time. Furthermore, we were unable to determine whether discharge to an SNF represented a change in living status or whether a given patient resided in an SNF before surgery. Another potential limitation is the use of payments as a proxy estimate of costs rather than assessing costs directly in the health care setting. Nevertheless, this is the first study to assess the trend and certain aspects of the associated burden of the surgical treatment of LSS in the working-age US population. We believe that these results identify an important trend in this age group in which outcomes can be very consequential.

\section{Conclusions}

Our results suggest a trend toward higher rates of arthrodesis and complex procedures for the treatment of isolated LSS, especially in the South and Midwest of the US. These surgeries were associated with more complications, higher payments, and a longer hospital stay. Given the lack 


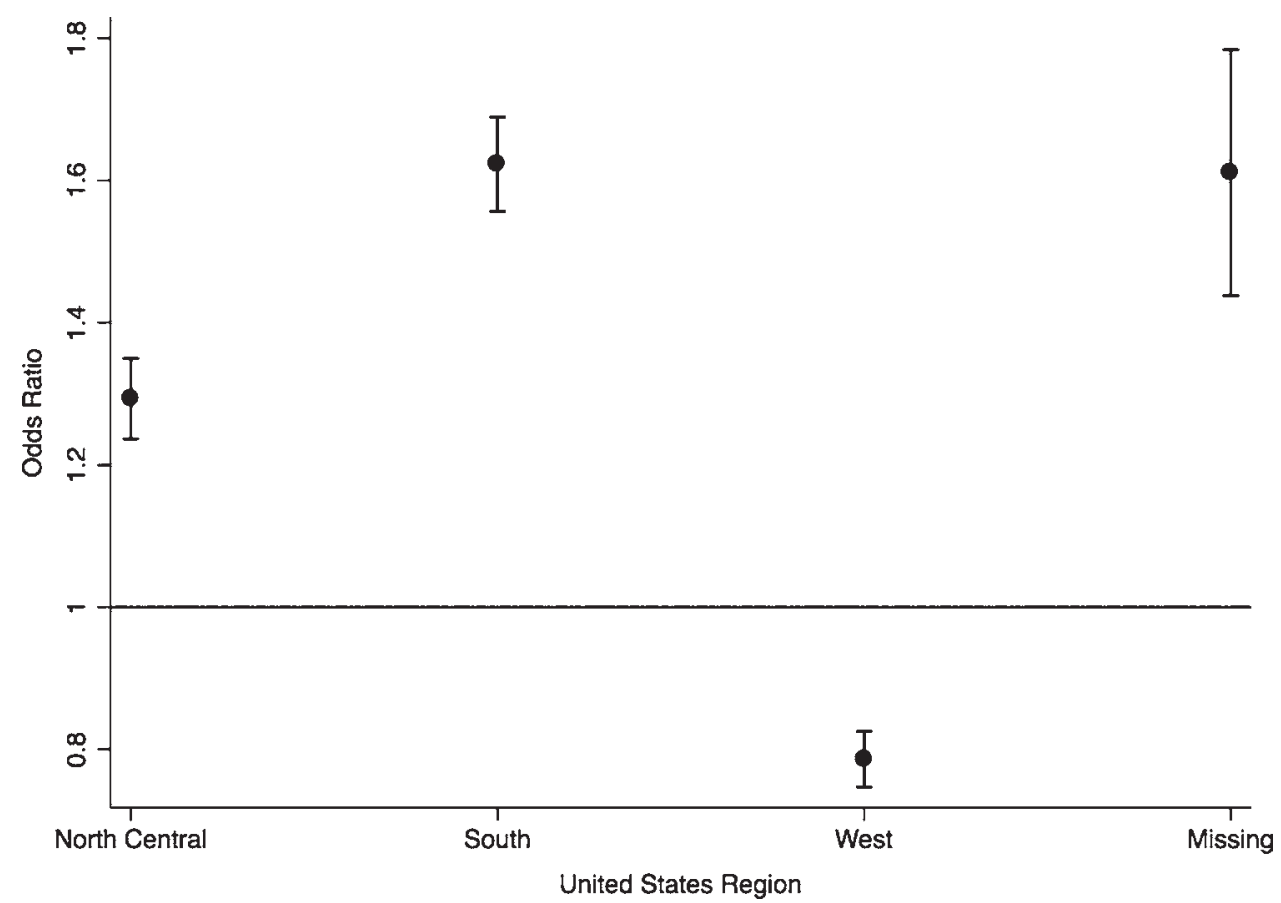

FIG. 2. Odds of undergoing decompression with arthrodesis for LSS by US region, using the Northeast region as the referent and adjusting for age, sex, and CCl. Error bars indicate $95 \% \mathrm{Cl}$. Data from Truven Health Analytics MarketScan Commercial Claims and Encounters Database for 2010-2014.

of strong recommendations for the treatment of this disease, ${ }^{16}$ further prospective studies and a thorough review of the current guidelines ${ }^{11}$ are needed to define a new and clearer standard of care.

\section{References}

1. Amundsen T, Weber H, Nordal HJ, Magnaes B, Abdelnoor M, Lilleâs F: Lumbar spinal stenosis: conservative or surgical management?: A prospective 10-year study. Spine (Phila Pa 1976) 25:1424-1436, 2000

2. Chang W, Yuwen P, Zhu Y, Wei N, Feng C, Zhang Y, et al: Effectiveness of decompression alone versus decompression plus fusion for lumbar spinal stenosis: a systematic review and meta-analysis. Arch Orthop Trauma Surg 137:637650, 2017

3. Ciol MA, Deyo RA, Howell E, Kreif S: An assessment of surgery for spinal stenosis: time trends, geographic variations, complications, and reoperations. J Am Geriatr Soc 44:285-290, 1996

4. Covaro A, Vilà-Canet G, de Frutos AG, Ubierna MT, Ciccolo F, Caceres E: Management of degenerative lumbar spinal stenosis: an evidence-based review. EFORT Open Rev 1:267-274, 2017

5. Deyo RA, Gray DT, Kreuter W, Mirza S, Martin BI: United States trends in lumbar fusion surgery for degenerative conditions. Spine (Phila Pa 1976) 30:1441-1447, 2005

6. Deyo RA, Mirza SK, Martin BI, Kreuter W, Goodman DC, Jarvik JG: Trends, major medical complications, and charges associated with surgery for lumbar spinal stenosis in older adults. JAMA 303:1259-1265, 2010

7. Försth P, Ólafsson G, Carlsson T, Frost A, Borgström F, Fritzell $\mathrm{P}$, et al: A randomized, controlled trial of fusion surgery for lumbar spinal stenosis. N Engl J Med 374:1413-1423, 2016

8. Hawker GA, Wright JG, Coyte PC, Williams JI, Harvey
B, Glazier R, et al: Determining the need for hip and knee arthroplasty: the role of clinical severity and patients' preferences. Med Care 39:206-216, 2001

9. Irwin ZN, Hilibrand A, Gustavel M, McLain R, Shaffer W, Myers M, et al: Variation in surgical decision making for degenerative spinal disorders. Part I: lumbar spine. Spine (Phila Pa 1976) 30:2208-2213, 2005

10. Katz JN, Lipson SJ, Lew RA, Grobler LJ, Weinstein JN, Brick GW, et al: Lumbar laminectomy alone or with instrumented or noninstrumented arthrodesis in degenerative lumbar spinal stenosis. Patient selection, costs, and surgical outcomes. Spine (Phila Pa 1976) 22:1123-1131, 1997

11. Kazemi N, Crew LK, Tredway TL: The future of spine surgery: new horizons in the treatment of spinal disorders. Surg Neurol Int 4 (Suppl 1):S15-S21, 2013

12. Kim J: The effects of demographic change on GDP growth in OECD economies. Federal Reserve Board IFDP Notes. September 28, 2016. (https://www.federalreserve.gov/ econresdata/notes/ifdp-notes/2016/effects-of-demographicchange-on-gdp-growth-in-oecd-economies-20160928.html) [Accessed January 30, 2018]

13. Loeser JD, Van Konkelenberg R, Volinn E, Cousins MJ: Small area analysis of lumbar spine surgery in South Australia. Aust N Z J Surg 63:14-19, 1993

14. Ma XL, Zhao XW, Ma JX, Li F, Wang Y, Lu B: Effectiveness of surgery versus conservative treatment for lumbar spinal stenosis: A system review and meta-analysis of randomized controlled trials. Int J Surg 44:329-338, 2017

15. Machado GC, Ferreira PH, Harris IA, Pinheiro MB, Koes BW, van Tulder M, et al: Effectiveness of surgery for lumbar spinal stenosis: a systematic review and meta-analysis. PLoS One 10:e0122800, 2015

16. Machado GC, Ferreira PH, Yoo RI, Harris IA, Pinheiro MB, Koes BW, et al: Surgical options for lumbar spinal stenosis. Cochrane Database Syst Rev 11:CD012421, 2016

17. Machado GC, Maher CG, Ferreira PH, Harris IA, Deyo RA, 
McKay D, et al: Trends, complications, and costs for hospital admission and surgery for lumbar spinal stenosis. Spine (Phila Pa 1976) 42:1737-1743, 2017

18. Malmivaara A, Slätis P, Heliövaara M, Sainio P, Kinnunen $\mathrm{H}$, Kankare J, et al: Surgical or nonoperative treatment for lumbar spinal stenosis? A randomized controlled trial. Spine (Phila Pa 1976) 32:1-8, 2007

19. Pålsson SH, Sandblom G: Influence of gender and socioeconomic background on the decision to perform gallstone surgery: a population-based register study. Scand J Gastroenterol 50:211-216, 2015

20. Resnick DK, Choudhri TF, Dailey AT, Groff MW, Khoo L, Matz PG, et al: Guidelines for the performance of fusion procedures for degenerative disease of the lumbar spine. Part 10: fusion following decompression in patients with stenosis without spondylolisthesis. J Neurosurg Spine 2:686-691, 2005

21. Smith DS, Krygiel J, Nease RF Jr, Sumner W II, Catalona WJ: Patient preferences for outcomes associated with surgical management of prostate cancer. J Urol 167:2117-2122, 2002

22. Taylor VM, Deyo RA, Cherkin DC, Kreuter W: Low back pain hospitalization. Recent United States trends and regional variations. Spine (Phila Pa 1976) 19:1207-1213, 1994

23. Weinstein JN, Lurie JD, Olson PR, Bronner KK, Fisher ES: United States' trends and regional variations in lumbar spine surgery: 1992-2003. Spine (Phila Pa 1976) 31:2707-2714, 2006

24. Weinstein JN, Tosteson TD, Lurie JD, Tosteson ANA, Blood
E, Hanscom B, et al: Surgical versus nonsurgical therapy for lumbar spinal stenosis. N Engl J Med 358:794-810, 2008

\section{Disclosures}

Dr. Neuman received non-study-related research or clinical support from DePuy-Synthes. Dr. Sciubba is a consultant for Medtronic, DePuy-Synthes, Stryker, NuVasive, and K2M. Dr. Skolasky is a member of the North American Spine Society board and Associate Editor of Quality of Life Research.

\section{Author Contributions}

Conception and design: Raad, Skolasky, Riley. Acquisition of data: Raad, Donaldson. Analysis and interpretation of data: Raad, Skolasky. Drafting the article: Raad, Donaldson. Critically revising the article: Sciubba, Neuman, Kebaish, El Dafrawy. Reviewed submitted version of manuscript: all authors. Approved the final version of the manuscript on behalf of all authors: Skolasky. Statistical analysis: Raad. Administrative/technical/material support: Raad, Donaldson. Study supervision: Skolasky.

\section{Correspondence}

Richard L. Skolasky: The Johns Hopkins University, Baltimore, MD.rskolas1@jhmi.edu. 